\section{Getting a GRP on asthma}

\section{By Kai-Jye Lou, Staff Writer}

Researchers at the Duke University School of Medicine have shown that a small molecule blocker of gastrin-releasing peptide, originally identified as a tumor growth inhibitor by researchers at the National Cancer Institute, attenuates multiple parameters of asthma with an overall effect that is stronger and longer lasting than that of corticosteroids. ${ }^{1}$ The compound was effective in two validated mouse asthma models, which is uncommon among drug classes marketed for the indication. The findings suggest that the peptide could be a new target for asthma, and the group is now working to elucidate the mechanism of its candidate compound.

Gastrin-releasing peptide (GRP) regulates normal fetal lung development ${ }^{2,3}$ but also has bronchoconstrictive effects. Excessive levels of GRP have been associated with various inflammatory lung conditions in humans, including bronchopulmonary dysplasia in infants. ${ }^{4,5}$

Because about $50 \%$ of infants with bronchopulmonary dysplasia develop asthma later in life, ${ }^{6}$ a Duke group led by Mary Sunday hypothesized that blocking GRP signaling could prevent clinical manifestations of asthma (see Figure 1, "A model of the GRP signaling cascade in asthma").

In mouse models of asthma triggered by either air pollution or allergens, prophylactic injections of a small molecule GRP blocker decreased multiple parameters of asthma compared with those in control animals.

The blocker, dubbed 77427, showed stronger effects than the corticosteroid dexamethasone across three key efficacy measures: airway hyperresponsiveness, inflammatory cell counts and cytokine levels in bronchoalveolar lavage fluid. The beneficial effects of 77427 persisted for at least three days.

Results were published in the Proceedings of the National Academy of Sciences.

"Our small molecule brought airway hyperresponsiveness back to baseline in validated models of the two major types of asthma," said Sunday, who is corresponding author on the paper.

Sunday, a professor in the Department of Pathology, of Medicine and of Pediatrics, said few drugs are able to bring airway hyperresponsiveness back to baseline. "In mice with allergic airway disease, for example, dexamethasone, only brings airway hyperresponsiveness down about halfway, but not all the way, to baseline," she told SciBX.

"Not many drugs work well for both types of asthma, except maybe the $\beta$-agonists," which are another widely used class of drugs

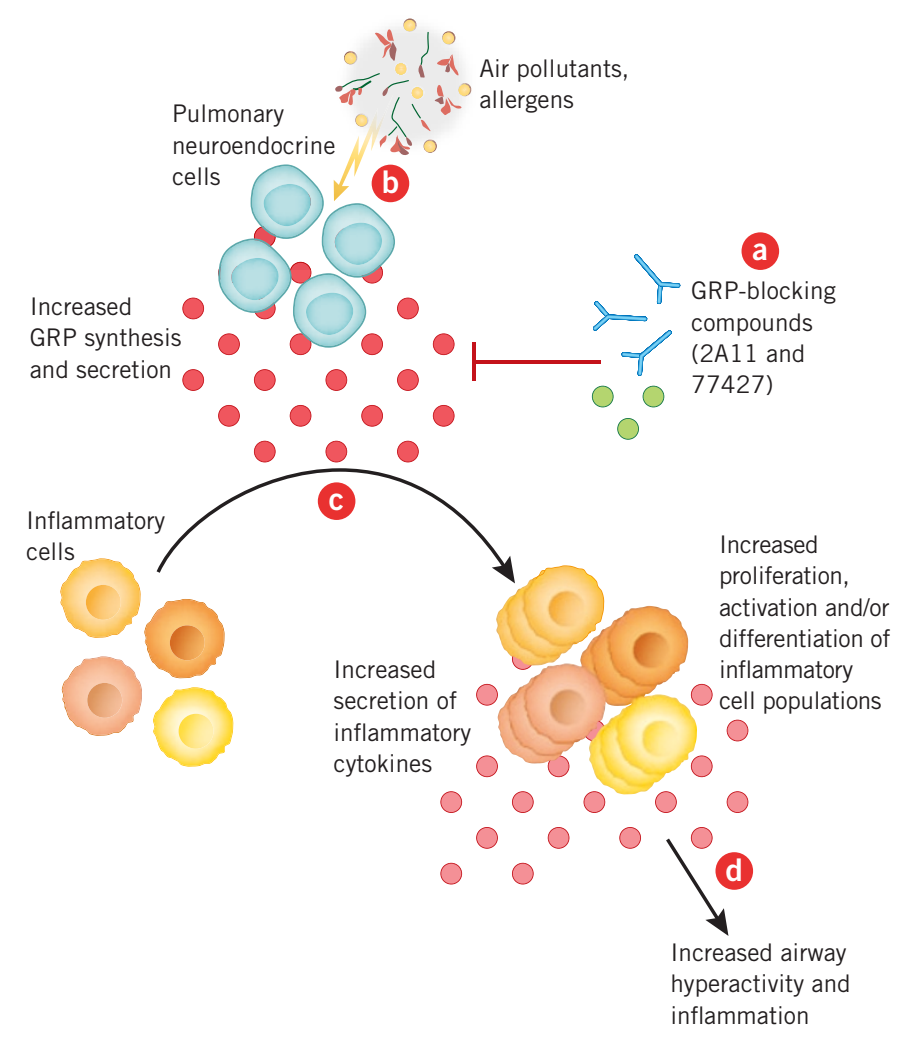

Figure 1. A model of the GRP signaling cascade in asthma. Pulmonary neuroendocrine cells are the only cell population within the lung known to produce gastrin-releasing peptide (GRP), which has bronchoconstrictive effects.

In the Proceedings of the National Academy of Sciences, researchers from the Duke University School of Medicine reported that blocking GRP signaling in mouse models of asthma decreased inflammatory cell and cytokine levels in airways and restored airway hyperresponsiveness (AHR) to baseline levels. The researchers also observed that a GRP-targeting small molecule (77427) or an antiGRP mAb (2A11) had a similar therapeutic effect that was superior to that of the standard-of-care agent dexamethasone [a].

Based on its findings, the group thinks that allergens and air pollutants like ozone could trigger an immune response that begins with the stimulation of GRP synthesis and secretion by pulmonary neuroendocrine cells [b]. The elevated GRP levels could promote the influx of inflammatory cells into the lung [c]. Moreover, GRP is known to induce proliferation, activation, differentiation and cytokine release in various inflammatory cell populations [d], which could contribute to asthmatic exacerbations.

for the disease, Sunday added. "Our mouse data thus suggest that the GRP-blocking small molecule could be more effective than corticosteroids and thus could be effective in treating a broader patient population. A GRP-blocking drug could also be an option for 
patients who are nonresponsive to $\beta$-agonists or corticosteroids."

"Any different mechanism that could have an additive effect with current treatments could be worth pursuing," said Gretchen Bain, executive director of biology at Amira Pharmaceuticals Inc. "If the tested compound works as well in humans as it did in the mouse models, it could become a steroid-sparing treatment, which is going to be a good thing."

Bain also liked that the Duke group's GRP inhibitor significantly decreased the number of inflammatory cells such as neutrophils, which are known to be resistant to corticosteroids. She added that Amira's 5-lipoxygenase activating protein (FLAP; ALOX5AP) inhibitors also have been shown to reduce inflammatory cell populations.

Amira has an undisclosed next-generation FLAP inhibitor in Phase II testing for asthma. The compound is partnered with GlaxoSmithKline plc. The biotech is seeking a partner for AM211, a prostaglandin $\mathrm{D}_{2}$ receptor 44 (CRTH2; GPR44; CD294; DP2) subtype DP2 antagonist in Phase I testing to treat asthma and chronic obstructive pulmonary disease (COPD).

NCI researchers led by Frank Cuttitta originally identified 77427 during a 2004 screening study using a GRP-neutralizing antibody. They followed up with a 2005 study showing that the compound inhibited tumor growth in mouse lung cancer models. ${ }^{7,8}$ Cuttitta is a coauthor on the PNAS paper and director of the angiogenesis core facility at the NCI.

Researchers have already evaluated the GRP-neutralizing antibody from the 2004 study in two NCI-sponsored clinical trials in small cell lung cancer (SCLC), ${ }^{9,10}$ but further development of the antibody in that indication was not pursued due to high cost, the inability to predict responsiveness and low efficacy. She said the group's NCI collaborators are still pursuing the development of small molecule GRP inhibitors, including 77427, primarily for cancer.

In the current study, the Duke researchers used the same GRPneutralizing antibody, called 2A11, in a parallel set of validation studies and showed that its effects were comparable with those of the small molecule 77427 in the mouse asthma models.

\section{Please comply}

According to Sunday, 77427 has drug-like properties that would make it a good candidate for clinical evaluation. The compound's low molecular mass of $139 \mathrm{Da}$ makes it amenable for aerosolized delivery. She also said the molecule appears to be biologically stable in vivo and is easily and inexpensively synthesized via a two-step reaction.

The compound's prolonged duration of effect suggests that 77427 may need to be dosed only two or three times a week. Corticosteroids are dosed daily or twice daily.
That edge could be important, noted Amira's Bain, because poor adherence to dosing schedules is one of the primary reasons that about half of asthma patients have uncontrolled disease. "When taken properly, $\beta$-agonists and corticosteroids actually work pretty well," but compliance to daily inhaler use is low, she said.

Sunday thinks both formulation strategies could come to the table.

"While it's too early to say at this time which formulation strategy would be best for small molecule, GRP-blocking agents, aerosol delivery has the benefit of being able to deliver much higher doses directly to the lung, which could enhance efficacy and reduce systemic exposure," she told SciBX.

Although the NCI collaborators have been generating 77427 analogs and derivatives, Sunday said 77427 thus far appears to be the most promising developmental candidate.

Her group's next steps are to better understand how 77427 exerts its therapeutic effects in mice and the relevance of GRP to asthma in humans. "We also want to determine which cells and cytokines are most relevant to GRP-induced disease symptoms in humans," she said.

Sunday's group also plans to run additional preclinical studies to evaluate the safety and toxicity of 77427 and determine how the small molecule is metabolized.

Duke has a pending patent covering compounds that block GRP signaling in inflammatory lung diseases. The work is available for licensing.

Lou, K.-J. SciBX 4(6); doi:10.1038/scibx.2011.152

Published online Feb. 10, 2011

\section{REFERENCES}

1. Zhou, S. et al. Proc. Natl. Acad. Sci. USA; published online Jan. 17, 2011; doi:10.1073/pnas.1014792108

Contact: Mary E. Sunday, Duke University School of Medicine, Durham, N.C.

e-mail: mary.sunday@duke.edu

Contact: Shutang Zhou, same affiliation as above e-mail: shutang.zhou@duke.edu

2. Sunday, M.E. et al. Am. J. Respir. Cell Mol. Biol. 3, 199-205 (1990)

3. King, K.A. et al. Proc. Natl. Acad. Sci. USA 92, 4357-4361 (1995)

4. Sunday, M.E. et al. J. Clin. Invest. 102, 584-594 (1998)

5. Subramaniam, M. et al. Am. J. Respir. Crit. Care Med. 176, 902-912 (2007)

6. Ng, D.K.-K. et al. Pediatr. Int. 42, 603-607 (2000)

7. Martínez, A. et al. Endocrinology 145, 3858-3865 (2004)

8. Martínez, A. et al. Oncogene 24, 4106-4113 (2005)

9. Kelley, M.J. et al. Chest 112, 256-261 (1997)

10. Chaudhry, A. et al. Clin. Cancer Res. 5, 3385-3393 (1999)

COMPANIES AND INSTITUTIONS MENTIONED

Amira Pharmaceuticals Inc., San Diego, Calif.

Duke University School of Medicine, Durham, N.C. GlaxoSmithKline plc (LSE:GSK; NYSE:GSK), London, U.K. National Cancer Institute, Bethesda, Md. 